\title{
The Future of Formal Retail in Sub-Saharan Africa: Brief Review and Opinion
}

\author{
Obino Mwamba1, Abubaker Qutieshat ${ }^{2}$ \\ ${ }^{1}$ University of Zambia, Lusaka, Zambia \\ ${ }^{2}$ University of Dundee, Dundee, UK \\ Email: obinomwamba@yahoo.com, abubaker@astrialearning.org
}

How to cite this paper: Mwamba, O., \& Qutieshat, A. (2021). The Future of Formal Retail in Sub-Saharan Africa: Brief Review and Opinion. Open Journal of Business and Management, 9, 1563-1571.

https://doi.org/10.4236/ojbm.2021.94084

Received: April 25, 2021

Accepted: June 13, 2021

Published: June 16, 2021

Copyright ( 2021 by author(s) and Scientific Research Publishing Inc. This work is licensed under the Creative Commons Attribution International License (CC BY 4.0).

http://creativecommons.org/licenses/by/4.0/

\section{(c) (i) Open Access}

\begin{abstract}
As Sub-Saharan Africa economies boomed in the early 90s, formal retail trade grew as well. However, most of the Sub-Saharan economies' wealth depends on commodity price performance which in turn has impeded the growth of retail sector. The focus on Africa from the major retailers' perspective has always been short-term. As the challenges continue eroding opportunities, many are re-thinking whether there is hope in the long-term. While there is no heterogeneity, as each country is at a different stage in retail development, challenges of inflation, forex shortages, poor infrastructure development, policy shifts, and general government inefficiencies are not uncommon. Almost 90\% of informal trade makes up the retail sector in Sub-Saharan Africa. The informal retail growth, riding on the political support of the governments, is crowding out the formalized retail growth. This work explores the body of existing knowledge on formalized retailing in Sub-Saharan Africa and focuses on how retailing has evolved in Sub-Saharan countries of Nigeria, Angola, South Africa, Zambia, and Malawi. The paper concludes by identifying the retail growth gaps from retail chains and the governments in the Sub-Saharan region. Recommendations for sustainability are highlighted. Future research gaps are equally identified to advance the understanding of formalized retail importance, challenges, and prospects for Sub-Saharan Africa.
\end{abstract}

\section{Keywords}

Commodity Price, Demographics, Formalized Retail, Informal Retail, Sub-Sahara

\section{Introduction}

Sub-Saharan Africa, home to $14 \%$ of the world's population, is estimated to grow more than China by 2030. Shopping in Sub-Saharan Africa is ever evolving with 
a blending of modern and ancient, formal, and informal retail trade. The early 90s introduced most Sub-Saharan Africa to the formal retail trade. With the liberalization of the economies in most countries to pursue market-based policies, retail chains started looking at Sub Saharan opportunities with fresh eyes. As SubSaharan Africa's economies boomed, the continent was labelled "the next Asia". While a few countries are still opening their formal retail sector with the spread in shopping malls, certain countries with promising formalized retail potential a few years earlier are presenting a groom outlook (Hugo, 2016).

Most of the Sub-Saharan countries have their growth tied to commodity price performance, with the recent declines ushering in slowness. Zambia is a good case in point. The copper boom is almost history, and the remaining mining companies are in cost-cutting measures. Retail businesses in Sub-Saharan African (both the consumer and retail markets) face a myriad of challenges. Slowing local economies, bottom-line pressure, new global competition, and ever-changing political and regulatory environments. In addition to all this, consumers are now in a position of power.

Consumers can access stores globally in the comfort of their homes. Using their mobile devices, they can now shop and pay for services. According to the Price water house PWC 2021 Retail and Consumer Report, the advent of social media changed how retailers engage and communicate with their customers (Hugo, 2016). Consumers have amassed power to influence the brand of a retail and consumer market. The question that begs answers as to whether we are nearing the end of physical stores as e-commerce takes center stage? The 2016 PWC report established that each African country is at a different stage in retail development with varied challenges and opportunities.

This review focus is on five countries: Nigeria, Angola, Zambia, South Africa, and Malawi.

Nigeria, South Africa, and Angola are Sub-Saharan Africa's largest economies in terms of Gross domestic product (GDP), with a rich endowment of natural resources. Zambia and Malawi have similar demographics but at different levels of formalized retail penetration. The five countries equally have a presence of ShopRite, Pepkor Africa, and Game stores. The growth of these household formal brands is a good case study for Sub-Saharan Africa.

\section{Literature Review}

Sub-Saharan Africa is striving to attain the 2063 goal of transforming the continent into a healthy, wealthy, and prosperous region (DeGhetto, Gray, \& Kiggundu, 2016). The business-as-usual mentality needs to shift towards addressing the perceived negative impact of informal trade on formal retailers with unfair competition being top of the list. In a recent survey of ten executives, Koroma, Newmarket, You, \& Ogalo (2017) distinguished unformalized retailing activities as those not covered by formal arrangements. Informal retailing includes the trade-in of legitimately produced goods that do not follow processes such as stan- 
dard business legislation or operational licenses. African governments have challenges regulating informal trade and thus lose the ever-needed revenue. Since their cost of doing business is relatively lower, informer traders can pass on the benefit to their consumers at the detriment of the overtaxed formal traders. Challenges of informality cut beyond the competition. Informality trade in Africa creates significant challenges for employers and employees concerning their rights. Most informal arrangements are less monitored for occupational safety, social protection, bargaining power, and social dialogue. Informality impedes strives to inclusive development promotion and the rule of law.

Deloitte (2021) identified four priority areas of focus for the sustenance of formal retail growth namely digital innovations to remain relevant in the new norm; supply chain resilience in times of disruption; health and safety strategies to create differentiation; and cost realignment opportunities.

Automation in the service industry is soon becoming the norm, so is high-tech convenience., stores will be present in the foreseeable future, though their existence will be for customer experience. The reality in the developing world (and particularly in the Sub-Saharan region) is different. While South Africa is probably among the most developed in retail technology, most consumers still prefer physical stores (Camarena, 2020).

A focus at five of the Sub-Saharan African countries reviews different levels of formal retail development. Nigeria, Angola, and South Africa are economic giants of sub-Saharan Africa. Zambia and Malawi are both landlocked with almost the same population size and culture. The two are, however, miles apart in formalized retail growth. Malawi brings a unique spectrum of being the least desired destination for international brands. The five countries have a presence of South African retail chains of Pepkor Africa and ShopRite. A comparison of the growth of these brands' footprint providing enough ground for analysis of the retail performance.

\subsection{Nigeria}

The West African formalized Retail landscape with its fragmentation is potentially underserved. The trend has attracted several retail giants to set up in the countries. The two West African attractive destinations are Nigeria and Ghana in terms of gross domestic growth. The Nigerian population and growing consumer market provide an attractive value proposition. The country's growing population and its rising middle class are attractive incentives for formal retailers. According to the United Nation's projections, Nigeria's population will increase from 198 million in 2018 to 400 million by 2050. The development will transform the country into the third most populated after India and China.

Nigeria is the largest African economy. The country's undoing is in its inefficiencies and infrastructural deficit. Inconsistency in power supply results in businesses running generators for an average of 10 hours per day. More shopping is happening from the ever-increasing informal markets, street stalls, and 
tabletops (Hugo, 2016).

Informal retailing represents $90 \%$ of the retail value in countries like Nigeria and Uganda. Although formal retailing has grown since early 2000, the retail sector is nonetheless; dominated by the informal sector. Traditional open markets and kiosks being drivers for informal retailing. Governments in these countries are coming to accept the informal sector as not disappearing anytime soon. A possible shift from the large retail mall concept to small formal neighborhood developments will support the formalized growth. It will guide more Nigerians into formalized retail space.

\subsection{Angola}

Angola has vast natural resources, but decades of civil wars and mismanagement have left the Sub-Saharan third-biggest economy with poor infrastructure and general macroeconomic instability. The economy is highly dependent on natural resources, particularly oil. Poor commodity prices on the world market ushering in slowness periodically (World Bank, 2018). According to Dublin (2020), The wholesale and retail of food con-tributes over $18 \%$ to Angola's GDP. The formal sector, together with large informal traders, creates around 1.7 million jobs. The recent heavy investment in supermarkets has seen food sales rising from less than 5\% in 2000 to between $20 \%$ and $30 \%$ in 2019 .

Angola presents an environment that is amongst the toughest. Though retail space is well developed, corruption, weak transport infra-structure, skill shortages, and a cumbersome regulatory environment is hindering retail growth (Hugo, 2016). With heavy investment in malls, the country has grown its formal retail space from 5\% in 2000; to around 30\% in 2019 (Dublin, 2020).

Consumer spending, employment, and middle-class growth are dependent on the performance of the oil sector. The current foreign exchange volatility has impacted food inflation, input prices, and rental space (Dublin, 2020). Therefore, many large retailers have struggled to maintain complete product offerings.

Shoprite CEO, Pieter Engelbrecht, bemoaned the ongoing forex shortages, currency devaluations, and rampant inflation in Angola. The non-South African Business units reported huge trading losses, with no foreseeable hope of recovery in the short term (Peacock, 2019).

Angola contributes around $40 \%$ to Shoprite turnover from non-South Africa revenue. The other three main contributors being Nigeria, Zambia, and Mozambique.

\subsection{Zambia}

Zambia has enjoyed a long period of political stability. The privatization driven by the Chiluba government in the early 90s saw the entry of more formal retail brands. According to Hugo (2016), the abolishment of exchange controls and enactment of tax incentives made the retail sector attractive. South African retail giants such as Shoprite, Dunns, Guys \& Girls, Ackermans, Bannets, and Su- 
preme furnishers all flocked in the country. By the year 2005, only Shoprite and Pep stores managed to remain in business.

They highlighted costs, repeated policy reversals as part of the challenges for the informal retail growth in Zambia. Labor market inefficiencies and high redundancy costs add to the challenges. The recent rise in inflation has left empty shelves in the formal retail sector with massive price adjustments to catch up with the free-falling Kwacha. Most households, despite the growth in supermarkets, still source their products from informal markets. The unregulated informal sector like Soweto and Chisokone markets are left to compete with formal retailers like Shoprite, Pick'n'Pay, Spar, Pep stores, Game stores, and Choppies.

The COVID-19 pandemic has not made it easier for formal retailers in countries like Zambia. The Edcon group has exited the country. So are many furniture, supermarkets, and fast-food formalized retailers. The trend is no different from other Sub-Saharan Africa. ShopRite is on the verge of exiting Nigeria while consolidating its operations in other African countries.

\subsection{South Africa}

South Africa stands out with the most developed formal retail sector. The country has a well-developed infrastructure and relatively stable policies. The garment manufacturing industry is, however, under competitive pressure with cheap material imports from China.

The 2020 retail consumer report by Hugo (2016) claims the remarkable progress seen since the country ended apartheid has lost momentum. The secondlargest economy in Africa has experienced weakened external demand and relatively muted commodity prices. With relatively stable exchange rates, the cost of doing business in South Africa, unlike other Sub-Saharan country's is much lower.

The retail sector is globally changing at an exponential pace. Online trade, particularly with the advent of covid-19, is becoming prevalent. Goga et al. (2019) reported that online platforms have revolutionized retailing in South Africa and globally. Retail brands and many more companies can reach unreached markets with a click of a button. South African online retail presence though small, compared to international markets, has seen rapid growth in scope and value. Though the industry has been growing with double digits, it was only $2 \%$ in 2019 . The expansion of e-commerce in South Africa was reportedly hindered in the past years, by poor internet quality and high prices. The coronavirus pandemic outbreak and resulting lockdowns have resulted in an unprecedented boom in online adoption. Research and Markets report of 2020 estimates a 40\% growth in 2020. Growth is further estimated to grow year-on-year in the region of $100 \%$. The industry in South Africa is believed to have long-term investment potential in technology and supply chain.

One of the major retailers in Sub-Saharan Africa is Shoprite holdings. Though the brand has a presence in 14 other African countries, $75 \%$ of its turnover is from South Africa. The dampened growth from the rest of Africa prompted 
Shoprite holdings CEO, Engelbrecht, to share their concerns on possible future hardships.

\subsection{Malawi}

Probably the least developed of the five countries. The country has only four ShopRite stores against twenty-four in neighboring Zambia, with almost the same population. Malawi has Seventeen Pep stores against eighty-two in Zambia. The other South African brands in the country are Game stores and Food-lovers with only two stores apiece. Mr. Price closed its doors in 2014, barely five years after opening. The brand had only two stores in five years. The country has four main malls: Chichiri, Gate mall, Mzuzu, and Game complex. Leaders need to take bold decisions to achieve higher growth rates in all sectors. Over-dependence on tobacco is not helping the country's overall economic performance.

The influx of Chinese traders has exploded the informal sector. Limbe market is one of such unregulated volume markets (World Bank, 2019).

Unlike the other countries, Malawi's retail space owners are not allowed by law to charge in foreign currency. Though the rentals are high, they are less affected by volatility in exchange rates. While the government using the Malawi revenue authority, has installed fiscal printers in all formalized retail outlets to ensure every sale gets accounted for tax purposes, no measures have been put in place to collect taxes from the informal.

With Malawian economic growth recovering from well-managed single-digit inflation, the government has a rare opportunity to reign in fiscal deficits and reduce domestic debt levels. The government can now create the necessary incentives for the private sector to invest in malls for a sustainable retail sector (Kathleen, Luc, Andrew, \& Isis, 2020). Malawi inflation has shown a better trend than neighbouring countries such as Zambia. It is more stable and is thus good for business.

\section{Discussion and Conclusion}

Sub-Saharan countries, despite the numerous challenges, are promising for retail development strategies. Most Sub-Saharan countries' gross domestic product values have been on the rise recently. With a fragile and ever-growing middle class, the myriad of infrastructural challenges resulting in a low density of physical stores, the Sub-Saharan retail sector is not short of challenges. Infrastructural challenges such as the lack of good roads, poor internet quality, primitive banking services impede the formalized retail growth. In Africa, the common phrase "challenge equals opportunity" can never be far from the truth. Global retailers are questioning this phrase nowadays as to whether there is indeed hope in the future after all.

Managing the cost of doing business will always be a focus for Sub-Saharan Africa retail chains. Expensive retail spaces and supply chain challenges make it almost impossible to maintain an acceptable bottom line. From formal retailers' 
perspective, the highest contributor to the cost of doing business is retail space. Sub-Saharan governments can borrow a leaf from Malawi, for instance, and enforce legal provisions for all property owners to quote only in local currency. Regardless of the top line, few retailers can sustain operations with a significant rental percentage to sales. Zambia and Angola have probably been the most hit in the corona pandemic. The Kwacha and Kwanza have poorly performed against major currencies. While the sales were on a downward trend, formal retailers had to part away with more Kwachas and Kwanzas for the same dollar-rated rental.

The challenging environment has given Sub-Saharan retailers and consumers opportunities to leverage the available business platforms. Numerous African countries have seen a rise in e-commerce in this digital world. African consumers and retailers are thus, leapfrogging to new business models with reduced reliance on bricks \& mortar stores. South Africa and Nigeria have improved their online trading over the years. With the advent of the corona pandemic, the brands have seen even more traffic through online trade. While Angola is striving, Zambia and Malawi's online presence is still in its infancy. Internet is perceived to be expensive, and poor internet quality has all contributed to the slow growth of the e-commerce sector.

There is room for a developed omnichannel in Sub-Saharan Africa. Consumers are savvy today and exposed to various brands across the globe through the internet. Flexibility is a tenet for modern retailers to remain relevant in the retail environment. Customers are still visiting physical stores for a good feel and touch of various products.

The other key aspect of retail growth is customer experience. Retailers need to offer a differentiated customer experience at every touch point of the customer's journey. Something the informal sector and other competing firms cannot copy easily. There is a need for retailers to develop a culture of giving more than is expected to consumers to maintain and grow the market share. While informal retailers are aggressive in customer service, they are limited in aspects like room for browsing, visual merchandising, and pricing.

Leaders use organizational culture to support the achievement of organizational goals. Organizational culture is another aspect key to influencing the retail environment, work patterns, performance, productivity, and profitability of formal retailers (Linnenluecke \& Griffiths, 2010). Culture cannot be easily copied and thus forms a major differentiating factor. It can become the key differentiating strategy for any organization. Bolboli and Reiche (2014) reported that more than 90 percent of retail start-ups fail due to poor cultural homogeneity among business managers in organizations.

The corona Pandemic disruptive period of 2019-2021 has exposed inefficiencies in retail supply chain management. Challenges in providing a complete product range in the corona disrupted environment can be lessened, to some extent, through local purchases. Though local sourcing comes with its quality and capacity challenges, over time, it can get better. Since repatriations and forex losses 
are predominantly an international retailer's headache in challenging times, buy local can alleviate these challenges, especially in the food industry and fastmoving consumer goods. Apparel is relatively difficult to source locally due to quality and fashion-related considerations.

The Sub-Saharan government is a stakeholder in the whole retail chain and must live up to expectations. While the industry contribution is more than $40 \%$ in South Africa, the retail contribution is relatively insignificant in a country with no commodity products like Malawi. With only the tobacco industry as the earner, Malawi should have done well to develop the retail sector. The much-needed government revenue can be raised; by transforming the informal trade to more formal formats. The formalized retailers are currently at the messy of informalized retailers. The formalized retailers pay taxes, which are passed on, to the consumers through the prices. The informal trader enjoys all the benefits on the other hand.

Retailers like ShopRite, Pick'n'Pay, Spar, FoodLovers, Choppies, Pepkor Africa, Game stores, Foschini group have brought sanity to the Sub-Saharan retailing industry. These formal retailing brands contribute to the country's social and economic prospects, and thus, governments are obligated to ensure their survival.

Chain retailers are not looking at Africa with the same eyes anymore. They claim planning in the volatile, uncertain, complex, and ambiguous African environment is highly challenging. Recently, the CEO of Shoprite Holdings (Africa's largest food retailer), Pieter Englebrecht, bemoaned the currency devaluation and general challenges in trading within Africa. While acknowledging the brand's interest in serving customers, Englebrecht pointed out that; the brand was not able to do so "at all costs". Unfortunately, major brands are now looking at South America as the next big thing, instead of growing their presence in SubSaharan Africa. An evaluation of marketing strategies that have enabled Pepkor Africa and Shoprite Holdings to continue with their footprint expansion in some of the perceived challenging Sub-Saharan countries can help more fully understand the retail industry. While the need for tax revenue is widely recognized, further research needs to be undertaken to understand the motivation (e.g., political, economic) to perpetuate informal commerce in Sub-Saharan countries.

\section{Conflicts of Interest}

The authors declare no conflicts of interest regarding the publication of this paper.

\section{References}

Bolboli, A. S., \& Reiche, M. (2014). Culture-Based Design and Implementation of Business Excellence. The TQM Journal, 26, 329-347.

https://doi.org/10.1108/TQM-01-2014-0015

Camarena, A. (2020). Future of Retail. Predictions for 2020. 
https://www.plugandplaytechcenter.com/resources/what-future-retail-these-are-our-pr edictions-2020/

DeGhetto, K., Gray, J. R., \& Kiggundu, M. N. (2016). The African Union's Agenda 2063: Aspirations, Challenges, and Opportunities for Management Research. Africa Journal of Management, 2, 93-116. https://doi.org/10.1080/23322373.2015.1127090

Deloitte (2021). 2021 Retail Industry Outlook. The New Rules of Retail. https://www2.deloitte.com/us/en/pages/consumer-business/articles/retail-distributionindustry-outlook.html

Dublin (2020). Wholesale and Retail of Food in Angola. https://www.businesswire.com/news/home/20200207005306/en/Angola-Wholesale-Ret ail-of-Food-2020

Goga, S., Paelo, A., \& Nyamwena, J. (2019). Online Retailing in South Africa: An Overview. https://www.semanticscholar.org/paper/Online-Retailing-in-South-Africa

Hugo, A. (2016). Retail and Consumer Industry Leader. https://www.pwc.co.za/retail-and-consumer

Kathleen, B., Luc, C., Andrew, D., \& Isis, G. (2020). Malawi Economic Monitor December 2020: Doing More with Less-Improving Service Delivery in Energy and Water. Lilongwe: World Bank.

Koroma, S., Newmarket, J., You, N., \& Ogalo, O. (2017). Formalization of Informal Trade in Africa. Trends, Experiences, and Social-Economic Impacts. Rome: Food and Agriculture Organization of the United Nations. http://www.fao.org/3/i7101e/i7101e.pdf

Linnenluecke, M., \& Griffiths, A. (2010). Beyond Adaptation: Resilience for Business in Light of Climate Change and Weather Extremes. Business \& Society, 49, 477-511. https://doi.org/10.1177\%2F0007650310368814

Peacock, B. (2019). Shoprite Slumps as Consumers Struggle in Angola and Nigeria. The African Report.

https://www.theafricareport.com/16430/shoprite-slumps-as-consumers-struggle-in-an gola-and-nigeria/

World Bank (2018). Angola: Systematic Country Diagnostic. Creating As-Sets for the Poor. https://www.openknowledge.worldbank.org

World Bank. (2019). Malawi Economic Monitor, June 2019: Charting a New Course. Washington DC: World Bank. 